\title{
LA EVALUACION DE LA PENALIZACIÓN AL DELINCUENTE ${ }^{1}$
}

Diego Becerril Ruiz

\author{
Departamento de Sociología. Universidad de Granada
}

Email: becerril@ugr.es

\begin{abstract}
RESUMEN: La percepción social sobre la penalización de los delitos resulta un elemento clave para comprender las dinámicas sociales y su relación con los procedimientos penales. Es utilizada como justificación a una política penalista expansionista, siempre cimentada sobre las preocupaciones o alarma social. El trabajo analiza la evolución de la suficiencia de los castigos durante la últimos 35 años (19802014) y la atribución de responsabilidades. Junto a la descripción y evolución, se ha construido un perfil de las personas favorables a endurecer los castigos.
\end{abstract}

La fuente de datos son secundarias, las encuestas realizadas por el Centro de Investigaciones Sociológicas (C.I.S.), los Eurobarómetros y la Encuesta Social Europea. El ámbito es nacional.

Las principales conclusiones son que la evaluación de la justicia como benevolente y la querencia de castigos más duros dibuja una tendencia de constante incremento, salvo excepcionales caídas. Esta actitud se muestra más acentuada entre las personas con bajo nivel de estudios, mujeres, de edad avanzada, ideológicamente de derecha, con ingresos inferiores y católicos.

La responsabilidad de los castigos insuficientes es mayoritariamente achacada a todo el sistema, salvo la policía, aunque más a los elementos estructurales (organización judicial, leyes) que a los funcionales (jueces, fiscales).

PALABRAS CLAVE: Opinión pública; Percepción de la severidad penal; Punitivismo

\footnotetext{
${ }^{1}$ El presente artículo se realiza en el marco del Proyecto de Investigación, financiado por el Ministerio de Ciencia e Innovación, DER2012 35860 "Variables para una moderna política criminal superadora de la contradicción expansionismo-reduccionismo de la pena de prisión".
} 
ABSTRACT: The social perception of the penalization of the crimes is a key to understanding the social dynamics and its relation to criminal proceedings element. It is used as a justification for criminal expansionist policy, always founded on worry or alarm. The paper analyzes the evolution of the sufficiency of punishment during the last 35 years (1980-2014) and the assignment of responsibilities. Next to the description and evolution has built a favorable profile people toughen punishment.

The data source are secondary, surveys conducted by the Centre for Sociological Research (CIS), the Eurobarometer and the European Social Survey. The scope is national.

The main conclusions are that the evaluation of justice as benevolent and fondness for harsher punishments draw a trend of steady increase, unless exceptional falls. This attitude is more pronounced among people with lower level of education, women, elderly, ideologically right, lower income and Catholics.

The responsibility of insufficient punishment is mainly ascribed to the entire system, except the police, although the structural elements (judicial organization laws) more than functional (judges, prosecutors).

KEYWORDS: Public opinion; Perception of criminal severity; punitivism 


\section{1.- INTRODUCCIÓN}

España es un país donde la población reclusa registra unos índices relativamente altos en comparación con su entorno europeo (Larrauri, 2009). Esto indica que la aplicación de penas se ha ido extendiendo cuantitativamente hacia la prisión, en una clara actitud expansionista. Tal situación contrasta con los indicadores de criminalidad, que no han aumentado sino que han descendido en los últimos años.

La opinión pública registra una demanda social de extensión de las penas de prisión y el endurecimiento de las leyes. Los políticos y gobernantes se encontrarían "obligados" a dar una adecuada respuesta a estos intereses sociales y, por ello, reformar con sentido expansionista el código penal. Al menos este es el proceso políticamente correcto, nunca mejor dicho, pero es cuestionable el sentido direccional de las iniciativas y demandas.

Lo cierto y verdad es que la opinión pública se ha convertido en un elemento clave para la configuración de las políticas penales-criminales, más aún que los indicadores objetivos. Las distintas reformas penales realizadas han estado justificadas sobre el impacto social de determinados casos, y es una argumentación que sigue empleándose en la actualidad. Ahora bien, en la mayoría de ocasiones, estas reacciones populares no responden a una opinión bien informada sino más bien determinada por imágenes o impresiones derivadas de los medios de comunicación (Varona, 2011).

Y no es únicamente que la demanda social origine reformas legales. El estudio de las percepciones sociales tiene interés porque, en sentido contrario, la formulación de leyes y políticas concretas necesita de la aceptación y legitimación social para ser posible. 
A pesar de esta significación, como reconocen Roberts y Hough (2005), la investigación sobre estas actitudes no presenta una trayectoria dilatada a nivel internacional. Será en torno a los años 90 del pasado siglo cuando realmente aparezcan con fuerza las investigaciones sobre esta materia.

La atención hacia la opinión pública, en sus percepciones de la realidad penal, se enmarca dentro de un nuevo marco contextual de presencia de la delincuencia en lo cotidiano, teniendo los medios de comunicación un papel fundamental para condicionar el imaginario colectivo (Garland, 2001). Para Garland se ha instaurado una nueva cultura del control, donde el modelo punitivo se orienta a la incapacitación y no tanto a la resocialización. Un indicador, que interesa aquí especialmente, es el aumento del clima punitivo en la sociedad, donde se pierde la empatía con el delincuente y se origina el denominado populismo punitivo.

El contexto de origen se enmarcaría en unos parámetros muy concretos, bien definidos por Larrauri (2006:16):

1. La aparición de un fuerte neoliberalismo económico que impone una política de recortes y que gobierna por medio de un Estado punitivo. Este neoliberalismo provoca, en última instancia, la acentuación de las desigualdades sociales que propician el delito y condicionan una mayor sensación de inseguridad.

2. El surgimiento de un neoconservadurismo político. Se acentúa la peligrosidad de la delincuencia y la imagen del delincuente más amenazadora. Junto a esto, se destaca la responsabilidad individual del delito y la necesidad de castigo, que legitima la actuación del Estado.

3. Presencia de un sentimiento de inseguridad ontológica, determinado por la globalización, coexistencia de culturas y formas de vida, junto a la existencia de nuevos riesgos. Esta inseguridad, e incluso ansiedad, se proyecta contra el delito. El miedo cotidiano se transforma en indignación y se amplía el abanico de comportamientos y acciones que son delito. 
4. Aumento cualitativo y cuantitativo del delito, si bien este rasgo tiene muchos matices. El delito creció en número durante algunas décadas pero no es la pauta actual, aunque puede reconocerse que a nivel de opinión pública la idea persiste. Sí es patente el crecimiento de la población reclusa, con independencia de que responda a un aumento de la criminalidad o no. Si el populismo se mide como población reclusa sin duda se ha incrementado.

$\mathrm{El}$ aspecto cualitativo se refiere al nuevo carácter delictivo, que es internacional, organizado y violento.

Otros autores han confirmado estas mismas tendencias (Varona, 2009) que, en realidad, se han convertido en unas premisas de asunción básica entre los especialistas.

El populismo punitivo considera la justicia como demasiado benevolente, expresando que las penas impuestas a los delincuentes son demasiado blandas, mucho menor de lo que se merecen. A ello se añade la apreciación de que la pena impuesta no se cumple en general.

Otra dimensión crucial del populismo proviene de la utilización que los gobernantes realizan del Derecho Penal. En este nuevo marco de control, se considera que el aumento de las penas es una herramienta para disminuir el delito y, sobre todo, que atender a la demanda social significa un crédito de votos seguro. Como ya Garland advertía (2001), el nuevo modelo de control se caracteriza por la politización del delito y el sistema penal, enfocado hacia un uso electoralista.

En todo caso, el modelo de Garland no tiene por qué ser cierto e inevitable para todos los países. La propia Larrauri (2006) formula un alegato a todo lo contrario, a resistir frente a la "imposición" de este modelo.Y es que, a pesar de que no tiene por qué expandirse universalmente, tanto Larrauri (2009) como muchos criminólogos consideran que España secunda el modelo. Se sigue el sendero populista punitivo, verificándose que la población reclusa ha aumentado, las penas se han alargado, las 
libertades condicionales han disminuido y las clasificaciones de tercer grado han descendido.

La misma dirección confirman otros muchos autores. Entre los más recientes, el trabajo de Castaño (2014) cuestiona la política penal basada en el populismo y acusa a partidos políticos y medios de comunicación de favorecerlo.

La criminología española ha incorporado el interés por la opinión pública entre sus líneas de investigación. Como en el resto de países, no se contaba con una tradición de este tipo de estudio (Ruidíaz, 1994), lo que no impide que se haya configurado un interés creciente, como demuestra la aparición de trabajos centrados sobre este aspecto (Aizpurúa, 2011 y 2014; Varona, 2013). Algún autor considera incluso que las actitudes punitivas se convierten en el tema estrella de la criminología del siglo XXI (Varona, 2008).

En la actualidad se dispone de un cuerpo de investigaciones criminológicas focalizadas sobre la opinión pública. Algunas se centran en delitos concretos, como el caso de Aizpurúa (2014) que analiza la delincuencia juvenil o Marteache (2012) sobre la delincuencia sexual. Esta concreción permite destacar las connotaciones propias y el contexto social específico que condiciona la percepción.

La tendencia particular ha sido acompañada de otros trabajos generales como, por ejemplo, el de Varona (2009; 2013). Se destaca éste por ser uno de los más actuales y, sobre todo, por ser el más afín al presente análisis.

Efectivamente, Varona va a estar preocupado por definir cómo medir las actitudes punitivas en la opinión pública y la adecuación de los instrumentos utilizados. 
En su trabajo de 2009 realiza una revisión crítica de muy distintas formas de medir las actitudes punitivas. Hace referencia a la pregunta exacta que aquí se emplea centralmente (sobre la suficiencia de los castigos) y la calificará como pregunta-trampa para medir las actitudes punitivas. Entiende que es demasiado simple y que capta más punitividad de la que realmente existe. En realidad, la pregunta sobre suficiencia de castigos recogería la benevolencia o severidad del sistema penal, no propiamente el punitivismo que se mediría, stricto sensu, en la elección del tipo de castigo a través de un caso-escenario. A pesar de esta consideración, la pregunta sobre la suficiencia es básica y, prueba de ello, es que más tarde (2013), este mismo autor recupera sólo dos preguntas en sus análisis, siendo la suficiencia una de ellas. Es una dimensión esencial de la opinión pública, si bien no la considera propiamente medida del punitivismo.

Y es que el debate sobre el punitivismo y su medida no es baladí. Otro ejemplo, Larrauri (2009) entiende que el punitivismo es la tendencia a encarcelar, distinto de lo que sería la actitud hacia que se cumplan más años de cárcel. Para Larrauri el punitivismo se identifica con la tasa de encarcelamiento que no es consecuencia del aumento de los delitos sino de la política criminal y su carácter punitivo-expansionista.

Sin extendernos más en este debate, habría una consideración del punitivismo como actitud a imponer cárcel como castigo y que, aunque relacionada, la cuestión sobre la suficiencia de los castigos responde a la severidad/benevolencia del sistema.

En este trabajo consideramos que, efectivamente, ésta última pregunta, objeto

central de análisis, es una piedra angular para entender la opinión pública respecto al sistema penal. Se entiende que evalúa la percepción sobre la benevolencia, o no, de los castigos aplicados, la penalización. Cuestión a debate es si mide o no el punitivismo, que personalmente considero un concepto multifacético donde deben entrar diversos indicadores, entre ellos, aún con su carácter general, éste que se utiliza en este estudio. 
El problema es que muchas veces se adopta este indicador como reflejo absoluto e unívoco de las actitudes punitivas, lo que no es correcto (Serrano, 2011).

Aunque puede aducirse que es una percepción que no responde a la realidad o manejada por los medios de comunicación, no hay que olvidar que es una imagen social y que cómo bien advierte el teorema de Thomas, si las personas definen las situaciones como reales, éstas se vuelven reales en sus consecuencias.

Por otra parte, la evaluación de la penalización es una cuestión que tienen una trayectoria de 35 años en los análisis sociológicos, trayectoria que pocos temas pueden mostrar. Y no sólo es España sino que aparece con una formulación en las encuestas internacionales, como los eurobarómetros o las encuestas sociales europeas.

En España, salvo error, se ha analizado previamente este mismo indicador en cuatro ocasiones. En tres casos, Toharia $(1987 ; 1994)$ y Ruidíaz (1994) dentro de un planteamiento más general, como epígrafe parcial y con datos precisos de una actualización. El cuarto trabajo es de Varona (2013) que explora esta cuestión de forma más central en 9 estudios, 3 de ellos internacionales. Aquí completaremos el análisis con alguna cuestión afín, como la responsabilidad de la penalización, y se ampliaran las fuentes de datos a 19 estudios, de los que 7 son internacionales.

El análisis de nuestro objeto de estudio se realiza incorporando otras variables independientes. Entre los factores explicativos se han venido utilizando cinco grandes bloques (Aizpurúa, 2014). Corresponden a las variables sociodemográficas y personales, atribucionales, cognitivas, instrumentales y expresivas. De estos grupos, dado la disponibilidad y la limitación de las fuentes secundarias, se emplearan las variables sociodemográficas, si bien se entiende que son parte minoritaria del elenco que determina la percepción de la opinión pública respecto a esta cuestión. 


\section{2.- OBJETIVO E HIPOTESIS}

El objetivo general es investigar la evaluación de la penalización de la delincuencia en España. Se entiende que la pregunta sobre suficiencia de los castigos mide este rasgo.

Como objetivo específico, el estudio de la evolución de la opinión pública a este respecto y su atribución de responsabilidad. Es objetivo, asimismo, la construcción de un perfil de las personas con una actitud más punitiva ante los delitos, elaborado a partir de variables sociodemográficas y personales.

Por último, se pretende conocer el grado de predicción que estas variables poseen sobre la evaluación de la penalización.

Las hipótesis de partida son:

1. La evaluación de la penalización es más bien negativa, esto es, se piensa que existe una amplia benevolencia y se desea un mayor castigo para los delincuentes

2. Esta percepción se mantiene alta en el tiempo, si bien en los últimos años registra una tendencia al descenso (Varona, 2013)

3. La atribución de responsabilidad se adjudica a factores estructurales (políticos, gobierno, leyes,...) y no a factores más propiamente funcionales (jueces, fiscales, policías,..)(Toharia, 1987;1994)

Centrándose en los factores personales y sociodemográficos la investigación internacional permite extraer los principales hallazgos contrastables con los datos seleccionados. De todos los factores sociodemográficos, el nivel de estudios aparece como el más determinante. La tendencia que se registra es una correlación inversa, donde un nivel de estudios superior corresponde con una actitud menos punitiva (Gelb, 2011). 
La investigación indica que los varones se asocian con evaluaciones de la justicia como muy benevolente y solicitan más castigos que las mujeres (Aizpurúa, 2014; Varona, 2013), aunque excepcionalmente se verifica lo contrario (Payne y otros, 2004).

En atención a la edad, la relación identificada es que cuanto mayor edad más insuficientes se evalúan los castigos (Payne y otros, 2004), si bien no hay resultados conclusivos (Aizpurúa, 2014) y en ocasiones la relación aparece no significativa (Varona, 2008).

La ideología tiene una asociación clara, quienes se declaran como políticamente conservadores, a la derecha de la escala, son más punitivos (Gelb, 2011; Hartnagel y Templeton, 2012; King y Maruna, 2010; Toharia, 1994; Varona 2008;2013).

Sin embargo, para el factor religioso se registran resultados dispares, pudiéndo ser un factor que actúa más como un catalizador de las actitudes (Aizpurúa, 2014).

Por último, el estatus socioeconómico indica que las personas de menores ingresos serían quienes se declaran más partidarios de castigar más, aunque las diferencias fueron pequeñas (Gelb, 2011).

En resumen, la hipótesis inicial será que el perfil de persona que considera menos severa a la justicia es de pocos años de estudio, varón, de edad avanzada, en el espectro ideológico de la derecha y con ingresos bajos.

\section{3.- METODOLOGIA}




\section{Doctrina y Jurisprudencia}

La metodología utilizada se basa en el análisis de fuentes secundarias. Para ello se han obtenido los estudios del C.I.S. que habían preguntado por la opinión de la

suficiencia de los castigos. Esta cuestión venía formulándose desde 1980 con una relativa frecuencia, si bien desde 1998 no volvió a repetirse, con la excepción del 2011.Los estudios seleccionados son: 1.206 (1980); 1.305 (1982); 1.361 (1983); 1.401 (1984); 1.708 (1987a); 1.714 (1987b); 1.736 (1988); 1.847 (1989); 2.015 (1992); 2.133 (1995); 2.231 (1996); 2.278 (1998) y 2.861 (2011).

La falta de continuidad de los últimos años se ha compensado con la atención que el Eurobarómetro otorga a esta pregunta desde 2003. En concreto se han recuperado los datos de una serie que incluye los años 2003 (EB60); 2006(EB66); 2008 (EB69); 2012 (EB77) y 2014 (EB81). Como complemento, se han incluido la Encuesta Social Europea que en sus ediciones de 2008-2009(2008) y 2010-2011(2011) incluían una pregunta similar.

Una segunda comparación longitudinal, esta vez más limitada, se refiere a la opinión sobre quienes son los responsables de la falta de castigo, siendo una pregunta que sólo se realizaba a quienes previamente declaraban que los castigos son insuficientes.

Con anterioridad a 1994 el análisis de las bases de datos no es posible. Desde 1994 se emplea el análisis online del propio CIS y desde 1998 hay disponibilidad de microdatos. El multivariante (correlaciones y regresión logística) se ha realizado para los años 1998 y 2011. Se traza un perfil relacionado con las opiniones punitivas y la explicación que las variables sociodemográficas pueden aportar. La explotación de los datos se realiza con el programa SPSS. 


\section{Doctrina y Jurisprudencia}

La ventaja de la utilización de fuentes secundarias es su bajo coste y la posibilidad de trazar una serie durante un número significativo de años. A ello se añade que el nivel de cobertura es nacional. La principal limitación es que la pregunta se

inserta en un barómetro general, sin un desarrollo suficiente de otras cuestiones y con un nivel alto de abstracción.

\section{4.- RESULTADOS}

La evaluación de la penalización

El primer objetivo es el estudio de la evaluación de la penalización. Para este fin se deben dividir los datos anuales en dos grupos, los que corresponden al periodo 19801998 (Cuadro 1) y los comprendidos entre 2003-2014 (Cuadro 2). El motivo es que, si bien la pregunta es similar en todos los casos, las categorías de respuesta se modificaron. Entre 1980 y 1998 la respuesta era afirmativa o negativa respecto a la propuesta, mientras que desde 2003 se propone una escala de grado de acuerdo.

En referencia al primer periodo, existe una mayoritaria evaluación de que los castigos son insuficientes. Esta valoración aumenta bruscamente en 1984 y se mantiene relativamente estable hasta 1988, con un $73 \%$ de aprobación. En estos primeros cinco años sólo hay una excepción, que curiosamente corresponde al mismo año, 1987, que con tan solo un mes de diferencia en la medición da resultados muy diferentes. El descenso al 66\% puede deberse, seguramente, a que en ese mes se publicó una reforma del Código Penal (Ley Orgánica 6/1987) que pudo tener repercusión en el aumento de los satisfechos con los castigos. 


\section{Revista Internacional de \\ Doctrina y Jurisprudencia}

En 1989 esta satisfacción aumenta, bajando los disconformes, cuando de nuevo se realizan reformas en 1988 y 1989 (Ley Orgánica 3/1988; Ley Orgánica

3/1989). ${ }^{2}$ Ahora bien, a partir de 1989 se verifica un ascenso constante de quienes juzgan benevolente a la Justicia, porcentaje que no decae con la publicación de un nuevo Código Penal en 1995. Es la primera vez que una actuación legal no ha variado el porcentaje de insatisfechos con las penalizaciones.

\section{CUADRO 1: EVOLUCION DE LA EVALUACIÓN DE LA PENALIZACIÓN}

\begin{tabular}{|c|c|c|c|c|c|}
\hline & \multicolumn{5}{|c|}{ ¿Se castiga suficientemente a quienes cometen delitos? } \\
\hline Año & Sí & No & Ns & $\mathrm{Nc}$ & TOTAL \\
\hline 1980 & 18 & 60 & \multicolumn{2}{|c|}{22} & $100(\mathrm{~N}=6.032)$ \\
\hline 1982 & 28 & 53 & \multicolumn{2}{|c|}{19} & $100(\mathrm{~N}=4.985)$ \\
\hline 1983 & 29 & 55 & \multicolumn{2}{|c|}{16} & $100(\mathrm{~N}=1.724)$ \\
\hline 1984 & 13 & 72 & 14 & 1 & $100(\mathrm{~N}=2.595)$ \\
\hline $1987 \mathrm{a}$ & 22 & 66 & 10 & 2 & $100(\mathrm{~N}=2.499)$ \\
\hline $1987 b$ & 13 & 73 & 13 & 1 & $100(\mathrm{~N}=2.495)$ \\
\hline 1988 & 15 & 73 & 10 & 2 & $100(\mathrm{~N}=2.495)$ \\
\hline 1989 & 21,5 & 63,9 & 13 & 1,6 & $100(\mathrm{~N}=2.490)$ \\
\hline
\end{tabular}

${ }^{2}$ El barómetro de opinión del Consejo General del Poder Judicial verifica el descenso a partir de 1988. Su pregunta era el grado de acuerdo sobre que "con más mano dura se acabaría con el problema de la criminalidad". En 1986 estaban muy o bastante de acuerdo el 69\% de personas, pero desciende al 55\% en 1988 e incluso se mantiene estable, al 56\%, en 1990 (Toharia, 1990). 


\begin{tabular}{|c|c|c|c|c|c|}
\hline 1990 & 23 & 65 & 10 & 2 & $100(\mathrm{~N}=2.492)$ \\
\hline 1992 & 17 & 70 & 11 & 2 & $100(\mathrm{~N}=2.498)$ \\
\hline 1995 & 16,7 & 75,4 & 6,7 & 1,2 & $100(\mathrm{~N}=2.499)$ \\
\hline 1996 & 15,9 & 75,6 & 7,0 & 1,4 & $100(\mathrm{~N}=2.485)$ \\
\hline 1998 & 16,3 & 73,4 & 8,9 & 1,4 & $100(\mathrm{~N}=2.496)$ \\
\hline
\end{tabular}

Fuente: C.I.S. Elaboración propia. Datos previos a 1995 en Toharia $(1987 ; 1994)$

Otro dato que interesa destacar es el descenso significativo de las personas que no saben. Si al comienzo del periodo eran casi un quinto de los entrevistados, al final se sitúan en un $8 \%$. Esto significa que la opinión pública se atreve a opinar más sobre estas cuestiones, probablemente porque se considera informada y entienden que es un tema de su interés. El trasvase de este porcentaje ha ido, fundamentalmente, al grupo de los que desean más castigo.

Desde el año 1998 hasta la actualidad no se volvió a preguntar acerca de la evaluación de la penalización en el formato tradicional. El segundo periodo (2003-2014) se caracteriza por ser una etapa de encuestas internacionales, fundamentalmente el Eurobarómetro y dos estudios de la Encuesta Social Europa. El CIS únicamente repetirá la pregunta en 2011. Si bien la formulación es similar al periodo anterior, se modifican las categorías de respuestas, con una escala: muy de acuerdo; de acuerdo; ni de acuerdo ni en desacuerdo (ésta no en el Eurobarómetro); en desacuerdo y muy en desacuerdo.

La tendencia general de estos años del siglo XXI es un incremento constante de quienes evalúan insuficientes los castigos, que siendo altos en 2003 (79\%), todavía lo son más en 2014 (87\%). Y no sólo esa opinión se convierte en casi hegemónica, sino que sus defensores lo hacen con mayor convicción. La categoría que registra un ascenso superior es la de quienes están muy de acuerdo con castigar más, de un $44 \%$ en 2003 pasa a ser la mayoritaria en 2014 , con un $65 \%$. 


\section{Revistathermacional de \\ Doctrina y Jurisprudencia}

CUADRO 2: GRADO DE ACUERDO CON LA PENALIZACIÓN

\begin{tabular}{|c|c|c|c|c|c|c|c|c|}
\hline & \multicolumn{8}{|c|}{ Grado de acuerdo con la penalización más dura/severadel delincuente } \\
\hline & 2003 & 2006 & $2008 \mathrm{a}$ & $2008 b$ & $2011 \mathrm{a}$ & $2011 b$ & 2012 & 2014 \\
\hline Muy de Acuerdo & 44 & 46 & 51 & 44,8 & 25,3 & 26 & 61 & 65 \\
\hline De acuerdo & 35 & 35 & 34 & 39,3 & 50,1 & 45,3 & 27 & 22 \\
\hline Ni acuerdo ni desacuerdo & - & - & - & 10,3 & 15,9 & 9,7 & - & - \\
\hline En desacuerdo & 9 & 10 & 8 & 3,8 & 6,6 & 12,9 & 6 & 8 \\
\hline Muy en desacuerdo & 3 & 4 & 3 & 0,4 & 0,6 & 2,5 & 3 & 2 \\
\hline No sabe & 8 & 5 & 4 & 0,9 & 1,4 & 3,1 & 3 & 3 \\
\hline No contesta & - & - & - & 0,5 & 0,1 & 0,4 & - & - \\
\hline TOTAL & 100 & 100 & 100 & 100 & 100 & 100 & 100 & 100 \\
\hline $\mathrm{N}$ & 1.000 & 1.005 & 1.033 & 2.576 & 1.885 & 2.471 & 1.006 & 1.039 \\
\hline
\end{tabular}

Fuente: Eurostat:Eurobarómetros 60(2003);66(2006);69(2008a);77(2012);81(2014).

Encuesta Social Europea 2008-2009(2008b) y 2010-2011(2011a). CIS Estudio 2861(2011b)

En estos años es evidente la significación que tienen las reformas de 2010 que disminuyen significativamente el porcentaje de insatisfechos, aunque sea de forma temporal. A renglón seguido, la proporción de quienes quieren castigos superiores obtiene en 2012 su porcentaje record del 89\%. Para 2014 ha disminuido algo, quizás por las reformas que en 2013 aprueba el gobierno, pero que en la actualidad están en trámite parlamentario, por lo que quizás aún no han tenido impacto real en la opinión pública. 


\section{Doctrina y Jurisprudencia}

A pesar de la diferencias de organismos que hay en el Cuadro 2, los resultados son guiados fundamentalmente por los eurobarómetros. Cuando han coincidido con otras fuentes, como el año 2008 o 2011, es evidente una amplia similitud que hace confiar en la comparabilidad de los datos. Hay que tener en cuenta que la coincidencia de año no lo es de tiempo concreto en que se realiza la encuesta, por lo que el factor temporal puede incidir en las oscilaciones, en todo caso no muy relevantes.

Durante estos años se confirma, asimismo, la reducción progresiva de las personas que declaran no saber de la cuestión. En 2003 se registra un 8\% para progresivamente ir perdiendo peso hasta alcanzar en 2014 una cifra del 3\%, poco relevante.

Cómo resumen, el Gráfico 1 muestra la tendencia de las personas que evalúan la penalización como benevolente. Puede observarse claramente la tendencia al alza que no impide ciertos descensos en la línea que vuelven a recuperarse. Aun con las oscilaciones, la diferencia en estas décadas, desde 1980 a 2014 es de un $29 \%$.

\section{GRAFICO 1: LA EVALUACION DE LA PENALIZACIÓN EN ESPAÑA}

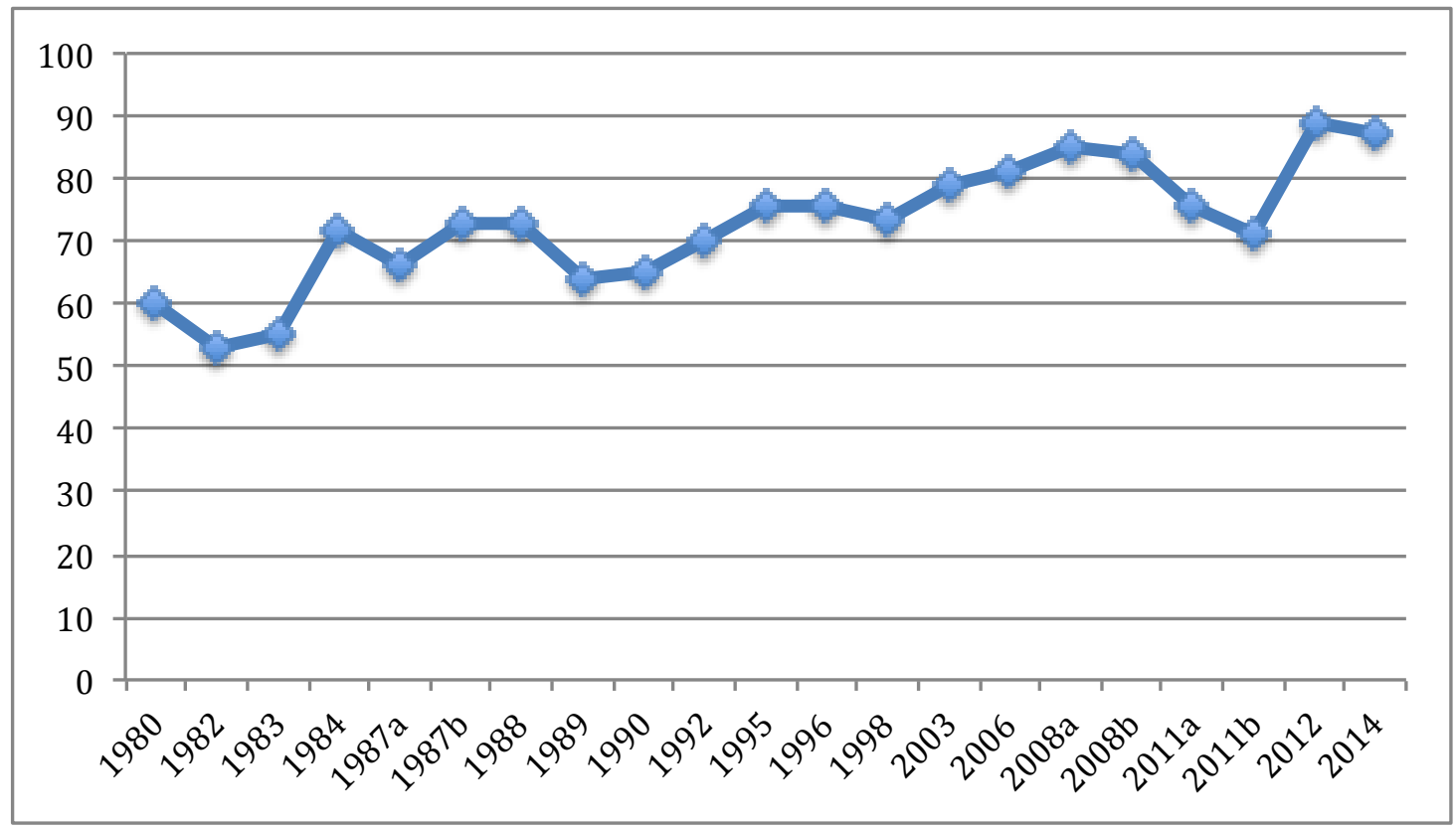

Fuente: C.I.S. Elaboración propia. Datos previos a 1995 en Toharia (1987;1994). A partir de 2003 se muestra la agregación de los muy de acuerdo y de acuerdo. 
Variables sociodemográficas y personales asociadas a la evaluación

Para la realización del análisis multivariante, y la elaboración de un perfil, se ha optado por trabajar con las encuestas del CIS. Estos estudios se soportan sobre una mayor muestra, más del doble que los eurobarómetros, y comparten una metodología idéntica. La limitación es que las bases de datos están disponibles desde 1998 y no antes. El resumen de las tablas de contingencia se presenta en el Cuadro 3.

Los datos de 1995 y 1996, al obtenerse del análisis online, no se ha podido calcular el chi-cuadrado, que sí se hace para el resto de años.

Si en primer lugar se atiende al nivel de estudios, éste se configura como el factor más significativo, cuya prueba de chi-cuadrado es cero absoluto en los dos años calculados. El resultado es que las personas con un nivel inferior, los comprendidos entre sin estudios y secundaria, son quienes registran un mayor acuerdo en castigar más a los delincuentes. En niveles altos, como medios universitarios o superiores, la actitud detectada es menos severa con los delincuentes. Si para el $76 \%$ de personas sin estudios la justicia debe ser más severa, esta misma idea sólo la subscribe el $63 \%$ con estudios medios universitarios o el $59 \%$ con superiores.

Esta misma relación es detallada en los distintos informes de los eurobarómetros y en la investigación previa (Gilb, 2011), se estaría en la misma línea.

Para el sexo, los datos iniciales de 1995 muestran una clara diferencia a favor de las mujeres, que desean, en mayor medida, unos castigos más severos. En el resto de años

las proporciones son más igualadas, si bien siempre continúa la mujer con un porcentaje algo superior, que en 1998 sería más significativo respecto a 2011. 


\section{Revistal hineracicional de \\ Doctrina y Jurisprudencia}

Tales datos sobre sexo son contrarios a las conclusiones previas de otros estudios españoles (Aizpurúa, 2014 y Varona, 2013) pero, sin embargo, si son coincidentes con estudios internacionales (Payne y otros, 2004). De la misma forma, el Eurobarómetro cuando ha destacado un sexo (2012), lo hace indicando que las mujeres son más proclives a endurecer los castigos.

\section{CUADRO 3: EVALUACIÓN DE LA PENALIZACIÓN SEGÚN VARIABLES}

\begin{tabular}{|c|c|c|c|c|}
\hline & 1995 & 1996 & 1998 & 2011 \\
\hline NIVEL DE ESTUDIOS & & & $* *$ & $* *$ \\
\hline Sin estudios & - & - & 79 & 76,8 \\
\hline Primaria & - & - & 74,8 & 72,8 \\
\hline Secundaria & - & - & 73 & 77,4 \\
\hline F.P. & - & - & 73,7 & 72,4 \\
\hline Medios universitarios & - & - & 69 & 63,8 \\
\hline Superiores & - & - & 61,3 & 59,6 \\
\hline$\underline{\mathrm{SEXO}}$ & & & $* *$ & $*$ \\
\hline Varón & 72,1 & 75,7 & 71,9 & 69,7 \\
\hline Mujer & 78,5 & 75,6 & 74,8 & 72,8 \\
\hline$\underline{\text { EDAD }}$ & & & $*$ & \\
\hline $18-24$ & 75,3 & 76,8 & 70,6 & 70,6 \\
\hline $25-34$ & 74,6 & 76,4 & 73,4 & 70,6 \\
\hline
\end{tabular}




\section{Doctrina y Jurisprudencia}

\begin{tabular}{|c|c|c|c|c|}
\hline $35-44$ & 73,7 & 74 & 72,1 & 72,6 \\
\hline $45-54$ & 76,2 & 77 & 74,5 & 68,5 \\
\hline $55-64$ & 76,6 & 78,1 & 77,4 & $\overline{72,3}$ \\
\hline 65 o más & 76,4 & 72 & 73,4 & $\overline{72,8}$ \\
\hline IDEOLOGIA & & & *** & *** \\
\hline Izq 1-2 & 74,9 & 75,9 & 73,4 & 62,5 \\
\hline $3-4$ & 73,9 & 74,4 & 69,6 & 67,8 \\
\hline $5-6$ & 75,0 & 76,1 & 74,8 & 72 \\
\hline$\overline{7-8}$ & 78,7 & 80,3 & 78,8 & $\overline{78,2}$ \\
\hline Dcha 9-10 & 81,5 & 79,7 & 89,1 & 79,7 \\
\hline RELIGION & & & & \\
\hline Católico & - & - & - & 73,1 \\
\hline Creyente otra religión & - & - & - & 64,4 \\
\hline No creyente & - & - & - & 65,6 \\
\hline Ateo & - & - & - & 65,7 \\
\hline $\begin{array}{c}\text { ESTATUS } \\
\text { SOCIOECONOMICO }\end{array}$ & & & $* *$ & ** \\
\hline Clase Media-Alta & 66,4 & $\overline{71,6}$ & 67,2 & 64,3 \\
\hline Nuevas clases medias & 75,6 & 79,3 & 69,8 & 73 \\
\hline
\end{tabular}




\begin{tabular}{|c|c|c|c|c|}
\hline Viejas clases medias & 75,9 & 76,7 & 76,6 & 75 \\
\hline Obreros cualificados & 76,3 & 76,6 & 75,9 & 70,8 \\
\hline Obreros no cualificados & 80,9 & 75 & 74 & 75,9 \\
\hline & & & & \\
\hline TOTAL & 75,4 & 75,6 & 73,5 & 71,3 \\
\hline
\end{tabular}

Fuente: C.I.S. Elaboración propia. Datos de 2011 (Muy de acuerdo + De acuerdo)

Chi-cuadrado * Menor de 0,05** Menor de 0,01

La edad por su parte no ha presentado unos datos conclusivos. Es posible dilucidar una tendencia a que las edades superiores están más disconformes con los castigos aplicados que los jóvenes, pero no es claro y sólo significativo para 1998. De hecho, tanto Aizpurúa (2014) como Varona (2013) refuerzan esta idea de poca claridad del efecto de la edad. Se pude considerar la tendencia que relaciona positivamente edad y dureza de los castigos, pero con menor fuerza que otras variables. La relación positiva entre edad y severidad sí se ha verificado en los Eurobarómetros y en la investigación de Payne y otros (2004).

Mucho más evidente es la relación con la ideología. Para todos los años analizados y de forma significativa, son las personas que se aproximan a la derecha quienes aumentan su deseo de endurecer las penas. En 2011 mientras el 79\% de los situados en la derecha percibían que la justica es blanda, en la izquierda secundaban esta idea el $62 \%$. Todos los estudios criminológicos confirmarían esta realidad, al igual que siempre es señalada en los informes de los Eurobarómetros.

La religión sólo fue posible comprobarla para el año 2011. En estos datos se muestra con una relación no significativa, si bien los católicos serían las personas con mayor deseo de endurecer los castigos, frente a los creyentes de otras religiones, no creyentes y ateos. 
Finalmente, el estatus socioeconómico se configura como otro factor significativo en todos los años. Los porcentajes señalan que los estatus medios-bajos y bajos son más partidarios de observar la justicia como blanda, mientras lo contrario aparece en los estatus altos. En concreto, si bien el 75\% de obreros no cualificados es partidario de ser más severo, entre la clase alta o media-alta el porcentaje disminuye al $64 \%$.

En los análisis, las correlaciones han sido significativas en 1998 y 2011. La diferencia es que en 1998 la significación era menor de 0,01 mientras que para 2011 sexo y edad pierden significación y la religión, incluida en 2011, no llega a ser significativa.

En las regresiones logísticas realizadas para los dos años las variables seleccionadas muestran escaso poder predictivo, entre 1\%-2\% de la varianza, siendo el nivel de estudios el más significativo junto al sexo.

\section{La responsabilidad de la benevolencia}

Más allá de que se considera a la justicia como benevolente y poco dura, un aspecto derivado es señalar al responsable de que no se castigue de forma adecuada. Esta pregunta proviene de un filtro, es decir, sólo contestaban quienes respondieron que no se castigaban suficientemente.

El ítem aparece entre 1983 y 1998, no volviendo a repetirse ni en España ni en las encuestas internacionales. A pesar de ello, es una información muy relacionada al objeto central y merece la pena aportarla pues existe durante 15 años. Este periodo, debido a las diferentes categorías de respuesta, se divide en dos segmentos. 


\section{Revistal hineracicional de \\ Doctrina y Jurisprudencia}

El primero abarca de 1983 a 1988 (Cuadro 4), donde se aludía a la culpabilidad, debiendo señalarse una respuesta única. Cuando se ha planteado así, la mitad de las personas han señalado al gobierno como responsable, y uno de cada cuatro a los jueces. Los porcentajes se han mantenido estables, y es de destacar la escasa responsabilidad que según los españoles tiene la policía de esta situación.

Desde 1989 a 1998 la pregunta se modificó, y se demanda el grado de responsabilidad que cada grupo, uno por uno, tiene en la insuficiencia de los castigos. Se han agrupado las respuestas de mucha y bastante responsabilidad, incluyendo un estudio de 1987 que ofrecía las mismas categorías de respuesta (Cuadro 5).

\section{CUADRO 4: RESPONSABILIDAD EN NO CASTIGAR SUFICIENTEMENTE}

\begin{tabular}{|c|c|c|c|c|}
\hline & \multicolumn{4}{|c|}{$\begin{array}{l}\text { ¿Quién cree que vd que es más culpable de que no se les castigue } \\
\text { suficientemente? }\end{array}$} \\
\hline & 1983 & 1984 & 1987 & 1988 \\
\hline Policía & 3 & 5 & 5 & 2 \\
\hline Gobierno & 47 & 43 & 47 & 50 \\
\hline Jueces & 10 & 25 & 24 & 24 \\
\hline Políticos & 12 & - & & - \\
\hline Fiscales & 1 & - & & - \\
\hline Abogados & 2 & - & & - \\
\hline Otros & 5 & - & & - \\
\hline No sabe & 18 & 23 & 19 & 20 \\
\hline
\end{tabular}




\begin{tabular}{|c|c|c|c|c|}
\hline No contesta & 2 & 4 & 5 & 4 \\
\hline TOTAL & 100 & 100 & 100 & 100 \\
$\mathrm{~N}$ & 660 & 1.869 & 1.818 & 1.827 \\
\hline
\end{tabular}

Fuente: C.I.S. Elaboración propia

\section{CUADRO 5: GRADO DE RESPONSABILIDAD EN NO CASTIGAR SUFICIENTEMENTE}

\begin{tabular}{|c|c|c|c|c|c|}
\hline & \multicolumn{5}{|c|}{ ¿Hasta que punto cree que vd que son responsables de que } \\
& \multicolumn{3}{|c|}{ no se castigue suficientemente a los delincuentes...? } \\
\hline & 1987 & 1989 & 1992 & 1996 & 1998 \\
\hline Policía & 23 & 21,6 & 25 & 18,9 & 20 \\
\hline Gobierno & 72 & 69,3 & 73 & 68,1 & 70,1 \\
\hline Jueces & 57 & 61,9 & 71 & 76,8 & 76,1 \\
\hline Políticos en general & 53 & 55 & 64 & - & - \\
\hline Fiscales & 42 & 44,6 & 57 & 66,1 & 65,3 \\
\hline Abogados & 39 & 43,1 & 54 & 56,8 & 60,1 \\
\hline Leyes penales & - & 71,8 & 75 & 83,2 & 84,8 \\
\hline & - & 75,4 & 78 & 80,3 & 82,7 \\
\hline
\end{tabular}

Fuente: C.I.S. Elaboración propia. Se mide por una escala, representándose en el cuadro la agregación de mucho y bastante.

De nuevo el gobierno inicia el periodo con un porcentaje destacado, pero es considerado progresivamente menos culpable que la organización de las leyes penales o la organización de la justicia. 
En estos años destaca la culpabilidad creciente que se asigna a los jueces, fiscales y abogados, que llegan a estar muy cerca de los máximos responsables. Por el contrario, la policía sigue siendo el grupo que menos culpa tiene y se mantiene estable en unos porcentajes relativamente bajos. El único donde no es mayoritaria la atribución de responsabilidad

Cuando se trata de buscar responsabilidades a lo largo de estos años, los españoles se la han asignado al sistema judicial, a las leyes penales $(84 \%)$ y a la propia organización de la justicia (82\%). Serían los elementos más estructurales del sistema judicial quienes soportan la mayor carga de culpa.

En segundo lugar, aunque no ha mucha distancia, se han situado los actores judiciales concretos, quienes realmente hacen justicia en lo cotidiano. Los principales señalados serían los jueces (76\%), seguidos de fiscales (65\%) y abogados (60\%).

Y no deja de ser reseñable que, con la introducción de los nuevos ítems, el gobierno ha "compartido" su culpabilidad, y su porcentaje de culpa se sitúa por debajo de los jueces, leyes y organización de la justicia. A ellos se añade que la culpabilidad de los políticos en general, que iba ascendiendo, dejo de preguntarse en los últimos años.

En todo caso, esta tendencia a culpabilizar a las leyes y la organización de la Justicia aparece desde el comienzo de los análisis. Se culpabiliza más no tanto a los encargados de la gestión cotidiana como a las bases legales, materiales y organizativas (Toharia, 1987). Los fallos se detectan como estructurales y no tanto funcionales.

La evolución temporal registra dos cambios. Por un lado el aumento de responsabilidad hacia la parte funcional (jueces, fiscales y abogados), que ha sido muy 
significativa, y ha situado su percepción de culpabilidad bastante cerca de la parte estructural. Aparece cada vez más una responsabilidad del sistema en su conjunto, el que podría cambiar la situación por su posición institucional (Toharia, 1994).

En segundo lugar, la pérdida y difuminación de la responsabilidad del gobierno. Desde cierta lógica sería el responsable último pero ha ido perdiendo peso o, más bien, se ha mantenido con la misma percepción a lo largo de los años, mientras el resto aumentaba porcentajes. De ser señalado destacadamente, pasa a ocupar un puesto medio de culpabilidad, más próximo a los menos culpables que a los máximos señalados.

En todo caso, los resultados se enmarcan dentro de un contexto general de evaluación negativa del funcionamiento de la justicia. El último barómetro realizado por el CGPJ (2008) señala que la imagen de la justicia empeora. Un 57\% cree que la justicia funciona mal o muy mal, dato que en 2005 representaba un 44\%, aumentando los quienes perciben un empeoramiento de la justicia (27\%), frente al $15 \%$ que pensaba lo mismo en 2005.

\section{5.- DISCUSION}

Ante los datos expuestos, es evidente que la opinión pública española expresa un deseo de mayor severidad en los castigos, al menos como imagen. Puede discutirse si la pregunta seleccionada, la evaluación de los castigos, es exactamente punitivismo o actitud punitiva, pero es indudable su continuo ascenso y presencia casi hegemónica entre la población. Mi opinión es que debe utilizarse como parte de un indicador complejo, como una expresión construida socialmente en abstracto, pero que mide una percepción arraigada. Para obtener el punitivismo habría que acudir a encuestas deliberativas o caso-escenario que vertebren principalmente el indicador, combinándolo con otras variables, como la presente. 
La pregunta examinada evalúa la penalización de los delincuentes, que podría considerarse una valoración de la eficacia del sistema penal para hacer que los delincuentes sientan el peso de ley (Toharia, 1987).

En cualquier caso, es preciso justificar el por qué de estos valores dominantes. Entiendo que la explicación debe basarse en varias razones:

1.- En primer lugar, la falta de información de las tendencias delictivas y el funcionamiento de la justicia. Aunque los entrevistados contestan mayoritariamente a la cuestión, y se han ido reduciendo quienes no saben o no contestan, esto no significa una formación suficiente. Son muchos los autores que apuntan en esta dirección y que detectan un amplio grado de desconocimiento de la estructura, organización y funcionamiento de la justicia en España (Ruidíaz, 1994; Toharia, 1990).La pregunta sobre los castigos puede estar captando el desconocimiento e incluso incomprensión de los ciudadanos ante el sistema judicial (Varona, 2008).

Aun así, añadiría, quienes están informados no suele ser de forma crítica o directa sino conducidos por los medios de comunicación, actor clave de las tendencias populistas. Cuando los ciudadanos están bien informados son menos punitivos y apuestan más por las medidas resocializadoras (Castaño, 2014).

2.- Precisamente el potencial de los medios de comunicación determina el grado de severidad. El problema de los medios es que no son transmisores de la opinión pública recogida en la sociedad, más bien son formadores de esta opinión. Los medios, a través de un tratamiento sensacionalista, crean situaciones de alarma social que no se corresponden con la realidad (Castaño, 2014). Su tratamiento de la información origina el ascenso del populismo punitivo. 
En esta misma línea, Varona (2011) desarrolla un análisis de cómo los medios condicionan con técnicas concretas. Identifica dos principales que serían la tematización de la agenda y el encuadre noticioso.

3.- La utilización política de la opinión pública y la instrumentalización del derecho penal. Los partidos políticos, por medio de los medios de comunicación, son determinantes claves que explican el hegemónico deseo de mayores castigos. No hay partido político significativo que no tenga medios de masas. En este sentido el estudio de Castaño (2014) es bastante explícito sobre las amplias posibilidades que tal alianza otorga. El eje tiene una dirección contraria a la que muchas veces se presenta. No es que

la opinión pública presione o demande a la política, es mas bien que la política introduce en la opinión pública las cuestiones, por medio de los medios de comunicación. Posteriormente, en "respuesta" a la opinión pública los políticos actúan. Hay una clara convergencia de intereses que, la mayoría de ocasiones, no parten de los políticos como tales, sino de asociaciones, profesionales, etc.. que actúan como lobbies políticos.

En segundo lugar, los partidos políticos entienden el derecho penal como un campo donde obtener votos. Interpretan que adoptando posturas más duras se obtiene un mayor apoyo popular.

Los tres factores: falta de información, medios de comunicación y partidos políticos son los ejes básicos donde se explica el auge de la severidad en los castigos. Lo mismo puede aplicarse al aumento general del punitivismo en la sociedad española. 
Ahora bien, el proceso de construcción de la percepción de los castigos no es simple. De entrada, en la sociedad puede decirse que hay una doble incomprensión. Una de los políticos respecto a la opinión pública, que creen que es más punitiva de lo que es; y otra de la opinión pública respecto el sistema penal, que apenas lo conocen y tienen imágenes distorsionadas (Larrauri, 2006)

Este mal entendimiento e incomprensiones origina una espiral ascendente que se desarrolla en dos sentidos. Por un lado agravando y endureciendo las penas, como medio de disminuir la sensación de benevolencia en la justicia. Por otro lado, ampliando las acciones o hechos que son delito.

En realidad, este proceso lo que provoca es un recorte de las libertades, que es muy cuestionado y cuestionable. Sin ir más lejos, el ejemplo de las reformas del código penal que aprobó el gobierno en 2013 representa otro paso. Su aprobación parlamentaria lleva más de un año estancada, prueba de la dificultad y dudas en el propio sistema.

Pero es que además, seguir por esa vía de endurecimiento y expansión de los delitos no soluciona el problema. Como se ha observado, por muchas reformas realizadas en España la querencia de mayor severidad no disminuye, salvo excepcional y temporalmente. No parece ser el camino.

Para dar respuesta a los altos porcentajes expuestos hay que comprender que la respuesta recogida en este trabajo deriva no sólo de la evaluación del sistema penal sino, con toda probabilidad, de un sentimiento de inseguridad o indefensión.

El miedo o la inseguridad que se instala en las sociedades postmodernas ante los múltiples riesgos con los que hay que convivir. Inseguridad ante la pérdida, por 
ejemplo, de integración o cohesión social. La errónea información y reacciones de rechazo ante la inmigración, culpada en gran medida de la delincuencia, es un caso típico (Varona, 2013). No obstante, si el político maneja estas actitudes y endurece el derecho penal no arregla el problema, pues estos riesgos son cíclicos e infinitos. Lo único que consigue es perjudicar a terceros y seguir alimentando la espiral hacia arriba.

\section{6.-CONCLUSIONES}

Las tres décadas y media de encuestas estadísticas reunidas forman una base sólida donde comprobar las hipótesis definidas al inicio. De hecho, a pesar de la similitud de algunas investigaciones, ningún trabajo previo había reunido tal número de estudios, ni siquiera considerando el periodo de años concreto en que cada investigación se enmarcaba.

Con esta información ha podido verificarse que entre los españoles existe una alta percepción de que la justicia es demasiado benevolente y que los castigos no son suficientes. La primera hipótesis planteada se confirmaría. Esta magnitud es alta comparada incluso con el entorno europeo. En 2014 España se sitúa en una posición media-alta (85\%), por debajo de países como Portugal (89\%) y aun alejados del máximo, representado por República Checa (95\%). Ahora bien, es una expresión de severidad superior a Italia (82\%, en la media de Europa) o Alemania (75\%) y distante del mínimo registrado en Suecia $(60 \%)$.

Nuestra segunda hipótesis pretendía conocer si la evolución ha marcado un descenso. Los datos han registrado que es cierto que, en ocasiones, esta evaluación negativa ha descendido, como ha mostrado el Gráfico 1. La tendencia general es un ascenso constante. En este sentido no se confirmarían las conclusiones de Varona (2013) ni la hipótesis inicial. En realidad, Toharia ya advertía (1994:41) que el 
"sentimiento" de que no se castiga suficientemente no es sólo ampliamente dominante sino que año a año se acentúa.

Cuestión distinta es que el ascenso sea lineal o presente oscilaciones. Las oscilaciones existen y, vistas desde una corta perspectiva, podría parecer que desciende el porcentaje, pero no es así. Estos descensos pueden asociarse con reformas del código penal que atenúan, en cierta medida, la demanda de más castigos, aunque vuelve a crecer posteriormente. Podría argumentarse que reformas del código suelen realizarse con frecuencia, casi todo los años, y no siempre afectan a la opinión pública. Cierto, pero es obvio que no todas tienen el mismo impacto y relevancia, y con ello me refiero tanto a lo legal como a lo social, impacto guiado por los medios de comunicación.

En tercer lugar, se planteaba como hipótesis la adjudicación de responsabilidad a factores estructurales y no tanto funcionales. Las encuestas han confirmado esta hipótesis pero las diferencias entre factores se han acortado. El aumento constante de las percepciones de falta de severidad produce que se culpe a todo el sistema, si bien algo menos a jueces y fiscales que a leyes y organización judicial. A este respecto, no deja de llamar la atención la relativa poca culpabilidad que se atribuye al gobierno y la excepción que se realiza con la policía.

En cuanto al perfil de personas próximas a aumentar los castigos se ha confirmado las asociaciones que la literatura apuntaba, salvo la excepción del sexo, donde los porcentajes son muy igualados, tendiendo más la mujer que el varón a evaluaciones más penalistas. Quizás la explicación es que la mujer tiene mayor sensación de inseguridad y miedo, lo que deriva en ser algo más propensa al endurecimiento de castigos. 
De todos los factores, el nivel de estudios es el más significativo. Puede ser debido a que, en niveles superiores, se interpretan los cambios sociales con mayor serenidad y herramientas (mayor información). De esta forma, la reacción a las inseguridades, ansiedades o riesgos sociales puede transformarse en una actitud menos punitiva. Los procesos sociales no son interpretados como negativos y amenazantes, sin despreciar que estos grupos sociales, probablemente, serán quienes afronten la vida con menos ansiedad e inseguridad.

Por su parte, la escala ideológica, con una determinación relevante, indica que las personas cercanas a la derecha son quienes se muestran más severas con los castigos. El resto de perfil se completa con la edad en relación positiva, a mas edad más severidad, la práctica religiosa católica y los estatus socioeconómicos bajos. De estas tres, sólo el estatus es significativo en 2011.

En todo caso, el aumento casi hegemónico de la opinión sobre la evaluación de la penalización ha determinado que muchas variables sociodemográficas se están debilitando o anulando, acercándose a tendencias más que a diferencias significativas.

Cabe preguntarse, llegados a este punto, ¿qué puede hacerse frente a esta hegemonía de la severidad?¿Todo castigo severo es mejor?

De entrada, habría que calibrar el multifacético punitivismo en su medida, pues con indicadores de caso-escenario las personas imponen penas similares o menores a los de los propios jueces. Además, son muy favorables a las penas alternativas de prisión y la rehabilitación. Quizás una cosa es la imagen social percibida y otra la realidad que, como muchas veces ocurre, no son acordes. Quizás el punitivismo es sólo una cuestión de percepción o evaluación, como aquí se muestra, pero la realidad contrastada e informada deja paso a un cierto mito del punitivismo (Varona, 2009;2013). 
Este trabajo quiere finalizar proponiendo acciones que ayudarían a desmontar el alza del populismo punitivo y disminuir esta percepción benevolente de la justicia.

En primer lugar, dado lo expuesto, es imprescindible transmitir de forma adecuada la información. La información sobre la justicia, su organización y funcionamiento, aunque sea a nivel básico. Las personas desinformadas son más vulnerables a los sentimientos espontáneos, al miedo y la inseguridad que conduce al populismo punitivo. Gran parte de la solicitud de severidad puede ser una expresión de cierta indignación o sentimiento de injusticia. El populismo se alimenta de la contradicción ente la gravedad del problema sentido y la imagen percibida de la respuesta del sistema penal. La solicitud de mayores castigos tiene un carácter instrumental que vehicula estas sensaciones, pero que no tiene en la mayor penalización su panacea.

La información puede/debe realizarse por los medios de comunicación pero abandonando el alarmismo y sensacionalismo del que demasiadas ocasiones hacen gala. En este sentido, tanto lobbies como partidos políticos deben comprometerse a intervenir de la forma más neutra posible, formando una opinión pública no mediatizada.

Otra acción de mejora sería promover que las personas participen más en el sistema judicial, en el marco de una justicia penal restaurativa. Participar, ser partícipe de la institución, aumentaría su conocimiento y ayudaría a disminuir el carácter punitivo. Quizás no debiera ser una participación populista pero sí generar una opinión pública meditada sobre las bases reales y racionales del problema.

De la misma manera, debe favorecerse el carácter resocializador de la pena e intentar poner en valor e incrementar las penas alternativas a prisión. 
Desde otra perspectiva, apelaría a la participación de los expertos en el sistema judicial penal, cuyas aportaciones teóricas y prácticas se han desacreditado (Díez Ripollés, 2004). Su participación más activa es probable que no tenga un impacto real, como suele ocurrir en el mundo académico, universo paralelo con las decisiones políticas. Pero es momento de reivindicar este debate y que se tome en consideración. Díez se queja de la marginalidad a la que llegan los expertos y lo fácil del debate entre el populismo y la politización. Como ilustración, en estos meses los expertos han participado en el debate de las reformas del código penal promovidas en 2013, siendo su evaluación muy distante a la propuesta política. Quizás se adopte su visión, o no, pero debe estar presente. En demasiadas ocasiones se confía en la racionalidad del sistema y es evidente que no siempre aparece.

La prueba de que esta medida sería eficaz es que la presencia de expertos o profesionales correlaciona con una políticas criminales más benignas (Larrauri, 2009).

En todo caso, los datos y propuestas deben considerarse en un contexto de relaciones complejas donde no es fácil definir las determinaciones y surgen múltiples interacciones.

Por ello, la última propuesta de futuro es la necesidad de investigar con otros conjuntos de factores e indicadores multidimensionales, que adopten una perspectiva longitudinal. Se deben desarrollar estudios específicos que combinen preguntas generales con otras de caso-escenario o grupo de discusión. Incluso de forma ideal se debería apostar por trabajar con encuestas deliberativas (Roberts y Hough, 2005; Green, 2006). Estas encuestas combinan las perspectivas cuantitativas y cualitativas obteniendo los mejores resultados. Cuando se han comparado la realización de cuestionarios con las encuestas deliberativas, éstas son menos punitivas y más estables en el tiempo, diferencias que deben analizarse en el futuro (Marteache, 2012). 


\section{REFERENCIAS BIBLIOGRAFICAS}

Aizpurúa, E. (2014). "Presente y futuro del estudio de la opinión pública hacia el castigo de los menores infractores. Evidencias, carencias y posibilidades”. Revista española de investigación criminológica $\mathrm{n}^{\circ}$ 12(3).

Aizpurúa, E. y Fernández, E. (2011).’Información, ¿antídoto frente al populismo punitivo?”, Revista española de investigación criminológica no 9(3).

Castaño Tierno, P. (2014).”¿Otra política penal es posible?. Un estudio sobre la viabilidad de una política criminal alternativa al populismo punitivo". Estudios penales y criminológicos 34:561-638

Díez Ripollés, J.L.(2004).“El nuevo modelo penal de la seguridad ciudadana”. Revista electrónica de ciencia penal y criminología. 06-03.

Garland, D. (2001). The culture of control. Crime and social order in contemporary society. New York. Oxford University Press.

Gelb, K. (2011). Predictors of punitiveness: Community views in Victoria. Melbourne. Sentencing Advisory Council.

Green, D.A. (2006).'Public opinión versus public judgement about crime. Correcting de "Comedy of errors"”, British Journal of Criminology 46:131-154.

Hartnagel, T.F. y Templeton, L.J. (2012). "Emotions about crime and attitudes to punishement”. Punishement and Society 14(4):452-474.

King, A. y Maruna, S. (2010).'Is a conservative just a liberal who has been mugged?.Exploring the origins of punitive views". Punishement and Society 11(2):147169.

Larrauri Pijoan, E. (2006).'Populismo punitivo...y como resistirlo". Jueces para la Democracia, 55:15-22. 
Larrauri Pijoan, E. (2009).'La economía política del castigo”. Revista electrónica de ciencia penal y criminología 11-06.

Marteache, N. (2012). "Deliberate processes and attitudes toward sex offenders in Spain”. European Journal of Criminology 9(2):159-175.

Payne, B.K. y otros (2004). "What drives punitive beliefs?. Demographic characteristics and justifications for sentencing.”. Journal of criminal Justice 32(3):195-206.

Roberts, J. \& Hough, M.(2005). Understanding public attitudes to criminal justice, New York, McGraw-Hill.

Ruidíaz García, C. (1994). "Los españoles ante la justicia penal: Actitudes y expectativas", REIS 67:219-240.

Serrano Maíllo, A. (2011). “Acerca de la medición de la firmeza frente al delito mediante preguntas únicas. Un análisis de clases latentes". Revista de derecho penal y criminología 6:295-360.

Toharia, J.J. (1987).¡Pleitos tengas!. Introducción a la cultural legal española. Madrid. Centro de investigaciones Sociológicas.

Toharia, J.J. (1990).Quinto barómetro de opinión del CGPJ. Madrid. Consejo General del Poder Judicial

Toharia, J.J. (1994). Actitudes de los españoles ante la Administración de Justicia. Madrid. CIS.

Varona Gómez, D. (2008).“Ciudadanos y actitudes punitivas: Un estudio piloto de población universitaria español”. Revista española de Investigación Criminológica 6(1).

Varona Gómez, D. (2009).”¿Somos los españoles punitivos? Actitudes punitivas y reforma penal en España”. Indret, Revista para el análisis del derecho 1

Varona Gómez, D. (2011).’Medios de comunicación y punitivismo”. Indret, Revista para el análisis del derecho 1 
Varona Gómez, D. (2013)."Percepción y elección del castigo en España: Resultados a partir de la Encuesta Social Europea (5ªEd.)”. Cuadernos de política criminal 111:145193 